\title{
Graft patency after open versus endoscopic saphenous vein harvest in coronary artery bypass grafting surgery: a systematic review and meta-analysis
}

\author{
Karishma Kodia ${ }^{1}$, Sinal Patel ${ }^{1}$, Matthew P. Weber ${ }^{1}$, Jessica G. Y. Luc ${ }^{2}$, Jae Hwan Choi ${ }^{1}$, Elizabeth J. Maynes ${ }^{1}$, \\ Syed-Saif Abbas Rizvi ${ }^{1}$, Dylan P. Horan ${ }^{1}$, H. Todd Massey ${ }^{1}$, John W. Entwistle ${ }^{1}$, Rohinton J. Morris ${ }^{1}$, \\ Vakhtang Tchantchaleishvili ${ }^{1}$ \\ ${ }^{1}$ Division of Cardiac Surgery, Thomas Jefferson University, Philadelphia, PA, USA; ${ }^{2}$ Division of Cardiovascular Surgery, Department of Surgery, \\ University of British Columbia, Vancouver, British Columbia, Canada \\ Correspondence to: Vakhtang Tchantchaleishvili, MD. Assistant Professor of Surgery, Division of Cardiothoracic Surgery, Thomas Jefferson \\ University, 1025 Walnut St, Suite 607, Philadelphia, PA, USA. Email: Vakhtang.Tchantchaleishvili@jefferson.edu.
}

\begin{abstract}
Background: Saphenous vein grafts (SVG) are a commonly used conduit for coronary artery bypass graft (CABG) surgery and can be harvested by either an open or endoscopic technique. Our goal was to evaluate long-term angiographic and clinical outcomes of open compared to endoscopic SVG harvest for CABG.

Methods: Electronic search was performed to identify all studies in the English literature that compared open and endoscopic SVG harvesting for CABG with at least one year of follow-up. The primary outcome was graft patency. Secondary outcomes included perioperative morbidity and mortality.

Results: Of 3,255 articles identified, a total of 11 studies were included for analysis. Of 18,131 patients, 10,873 (60\%) patients underwent open SVG harvest and 7,258 (40\%) patients underwent endoscopic SVG harvest. The mean age of patients was 65 years and $87 \%$ were male. The overall mean follow-up period was 2.6 years. During follow-up, patients who underwent open SVG harvest had superior graft patency per graft [open $82.3 \%$ vs. endoscopic 75.1\%; OR: 0.61 (95\% CI, 0.43-0.87); P=0.01], but higher rates of overall wound complications in the immediate post-operative period [open $3.3 \%$ s. endoscopic 1.1\%; OR: 0.02 (95\% CI, 0.01-0.06); $\mathrm{P}<0.001]$. Patients who underwent open SVG harvest had higher postoperative 30day mortality [open 3.4\% vs. endoscopic 2.1\%; OR: 0.59 (95\% CI, 0.37-0.94); P=0.03], but no significant difference in overall mortality [open 4.9\% vs. endoscopic 4.9\%; OR: 0.34 (95\% CI, 0.50-1.27); P=0.34].

Conclusions: Patients who underwent an open SVG harvest technique had improved graft patency and comparable overall mortality to endoscopic SVG harvest at average follow-up time of 2.6 years. Patients with open SVG harvest had higher rates of early wound complications and postoperative 30-day mortality, however, there was no difference in overall mortality.
\end{abstract}

Keywords: Coronary artery bypass grafting (CABG); saphenous vein harvest; endoscopic surgery; 30-day mortality; graft patency

Submitted May 17, 2018. Accepted for publication Jul 20, 2018.

doi: $10.21037 /$ acs.2018.07.05

View this article at: http://dx.doi.org/10.21037/acs.2018.07.05

\section{Introduction}

Coronary artery bypass grafting (CABG) surgery remains the most common procedure in adult cardiac surgery for coronary artery disease (1). Among arterial and venous conduits for CABG surgery, saphenous vein grafts (SVG) are the most commonly used conduit due to its superficial access site and decreased risk for bleeding compared to arterial conduits $(2,3)$. Traditionally, the SVG is harvested under direct vision (open harvest) with linear incisions along the course of the vein for clear vein visualization, 
mobilization and branch ligation (4-7). However, this approach carries an increased risk of wound complications including infection, hematomas, seromas and longer hospital length of stay (4-7).

The technique of endoscopic SVG harvesting was introduced in 1996 as a minimally invasive alternative to traditional open SVG harvesting (8). Multiple small randomized trials subsequently reported advantages of endoscopic SVG harvest as compared to open SVG harvest $(4,6,7,9,10)$. In 2005 , the International Society for Minimally Invasive Cardiothoracic Surgery published a consensus statement (11) that endorsed the use of endoscopic SVG harvest over open SVG harvest (class I, level B) to reduce wound related complications (class I, level A), improve patient satisfaction and postoperative pain (class I, level A) and reduce postoperative length of stay (class I, level A). Furthermore, the consensus statement (11) endorsed use of either endoscopic or open SVG harvest technique based on major adverse cardiac events and angiographic patency at 6 months (class IIa, level A). On the basis of these demonstrated advantages, endoscopic SVG harvest has now become the predominant mode of graft harvesting at many surgical centers (12).

In contrast to the abundant evidence demonstrating improved short-term and wound-related outcomes (6,7,13-16), observational analyses regarding the long-term patency rates of SVG harvested by endoscopic technique are conflicting and remain sparse. Endoscopic SVG harvest was reported to have similar short-term graft patency as open SVG harvest, but was concerning for a significantly reduced long-term graft patency at 12 months and beyond $(12,17,18)$. Because of the potential implications of worse long-term outcomes in patients who undergo CABG surgery, the role of endoscopic SVG harvest, although widely considered non-inferior to open harvest, has been a subject of much debate in the literature (19-21).

The aim of this systematic review was to evaluate longterm outcomes of patients who underwent CABG with open as compared to endoscopic SVG harvest techniques.

\section{Methods}

\section{Literature search strategy}

Thorough electronic searches were performed in March 2018 using Medline, Embase, Cochrane Central Register of Controlled Trials (CCTR), Cochrane Database of Systematic Reviews (CDSR), Web of Science, Scopus and CINAHL. To achieve the maximum sensitivity of the search strategy, we combined the terms: "coronary artery bypass graft (CABG)", "saphenous vein", "tissue and organ harvesting", "vein harvest", "endoscopic", and "minimally invasive" as either key words or MeSH terms. The reference lists of all retrieved articles were reviewed for further identification of potentially relevant studies and assessed using the inclusion and exclusion criteria.

\section{Selection criteria}

Eligible studies for the present systematic review and metaanalysis included double-arm studies that compared open and endoscopic SVG harvesting for CABG, with at least one year of follow-up time. Studies reporting on minimally invasive techniques other than endoscopic SVG harvesting were excluded. When institutions published duplicate studies with accumulating numbers of patients or increased lengths of follow-up, only the most complete reports with the longest follow-up were included for quantitative assessment. To ensure our results are reflective of current practice, only articles published from 1982 onwards were included. We excluded studies on patients $<18$ years of age, studies not published in the English language and those not involving human subjects. Furthermore, abstracts, case reports, conference presentations, editorials, reviews and expert opinions were also excluded.

\section{Definitions}

Graft patency per graft was determined using either FitzGibbon patency scale or by the exclusion of significant graft stenosis (22-24). Significant stenosis was defined as a greater than or equal to $50 \%$ stenosis as confirmed on follow-up catheterization (23).

\section{Data extraction and critical appraisal}

Data was extracted from article texts, tables and figures (S Patel, K Kodia). Discrepancies between the two reviewers were resolved by discussion and consensus.

\section{Statistical analysis}

A binary outcome meta-analysis of proportions was conducted for the available main perioperative and postoperative variables with logit transformation. Heterogeneity was evaluated using Cochran $\mathrm{Q}$ and $\mathrm{I}^{2}$ test. Meta-regression was conducted 


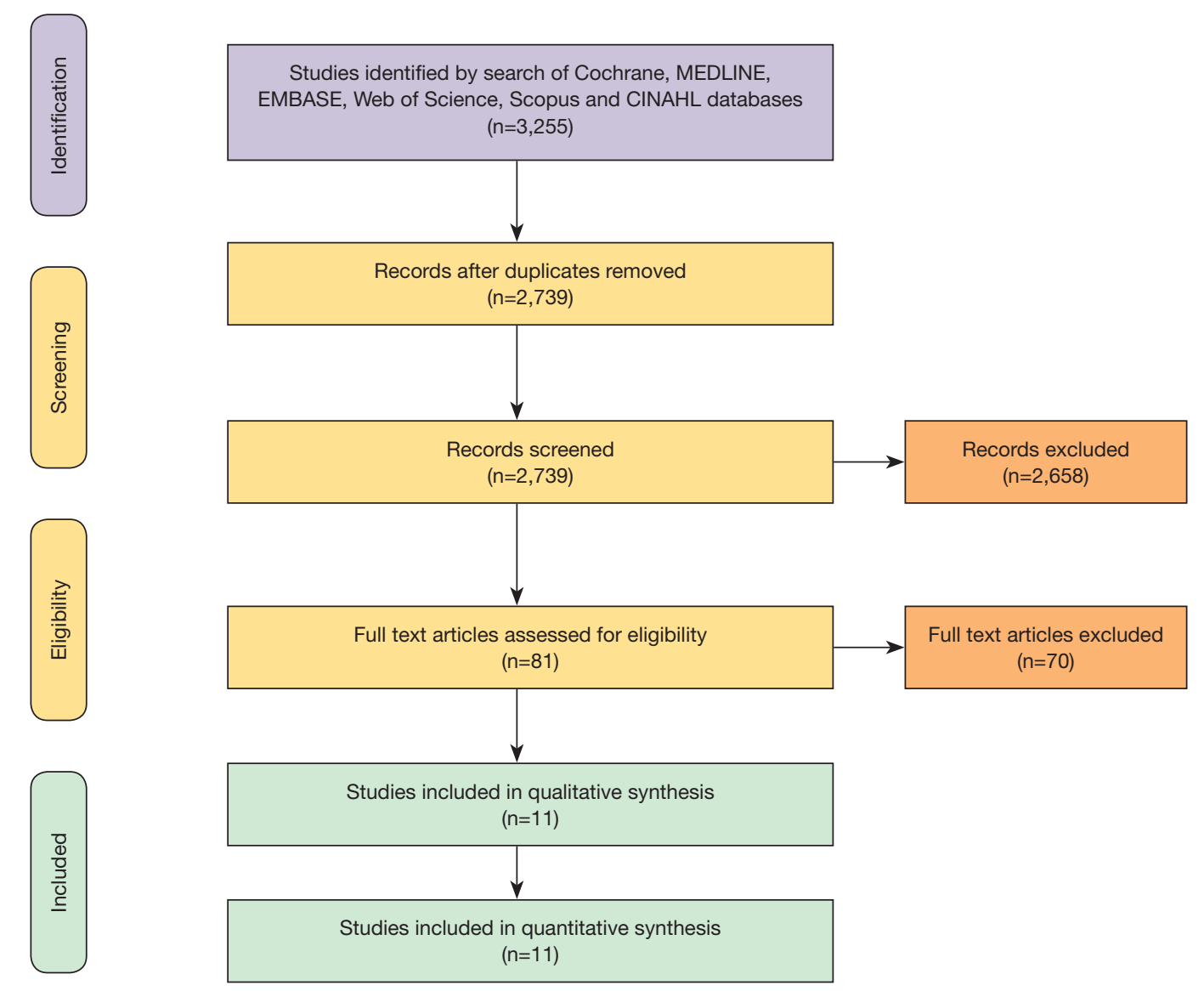

Figure 1 PRISMA schematic of search strategy. PRISMA, Preferred Reporting Items for Systematic Reviews and Meta-Analyses.

using open $v s$. endoscopic SVG harvest as a subgrouping variable. Egger's regression test for funnel plot asymmetry was performed to assess for publication bias. $\mathrm{R}$ software, version 3.01, (R Foundation for Statistical Computing, Vienna, Austria) was used for all data analysis and visualization. The meta-analysis was performed using metafor package for R. P values $<0.05$ were considered statistically significant.

\section{Results}

\section{Study characteristics}

Overall, 3,255 records were identified in a literature search of papers published between 1982 and present. Following application of the inclusion and exclusion criteria, 11 studies were included for analysis. Of the studies included, 5 were single-center retrospective studies, 3 were single-center prospective studies, and the remaining 3 were multicenter prospective clinical trials. Manual search of references did not yield further studies. A PRISMA flow diagram depicting the overall search strategy is shown in Figure 1. A detailed description of the studies used for analysis are reported in Table 1.

Of a total of 18,131 patients undergoing CABG, 10,873 (60\%) patients underwent open SVG harvest and 7,258 (40\%) patients underwent endoscopic SVG harvest. For graft patency subanalysis, $1,505(14 \%)$ patients in the open cohort and $1,744(24 \%)$ in the endoscopic cohort underwent angiography, follow-up evaluation for vein patency post-CABG surgery and were pooled for analysis. The overall mean follow-up period was 2.6 years. Mean angiographic follow-up time was 12.6 months [open 12.6 (95\% CI, 12.21-12.99) vs. endoscopic 12.6 (95\% CI, 12.20 12.99) months, $\mathrm{P}=0.34]$.

\section{Baseline demographics}

Baseline demographics of patients who underwent CABG with open and endoscopic SVG harvest techniques are 


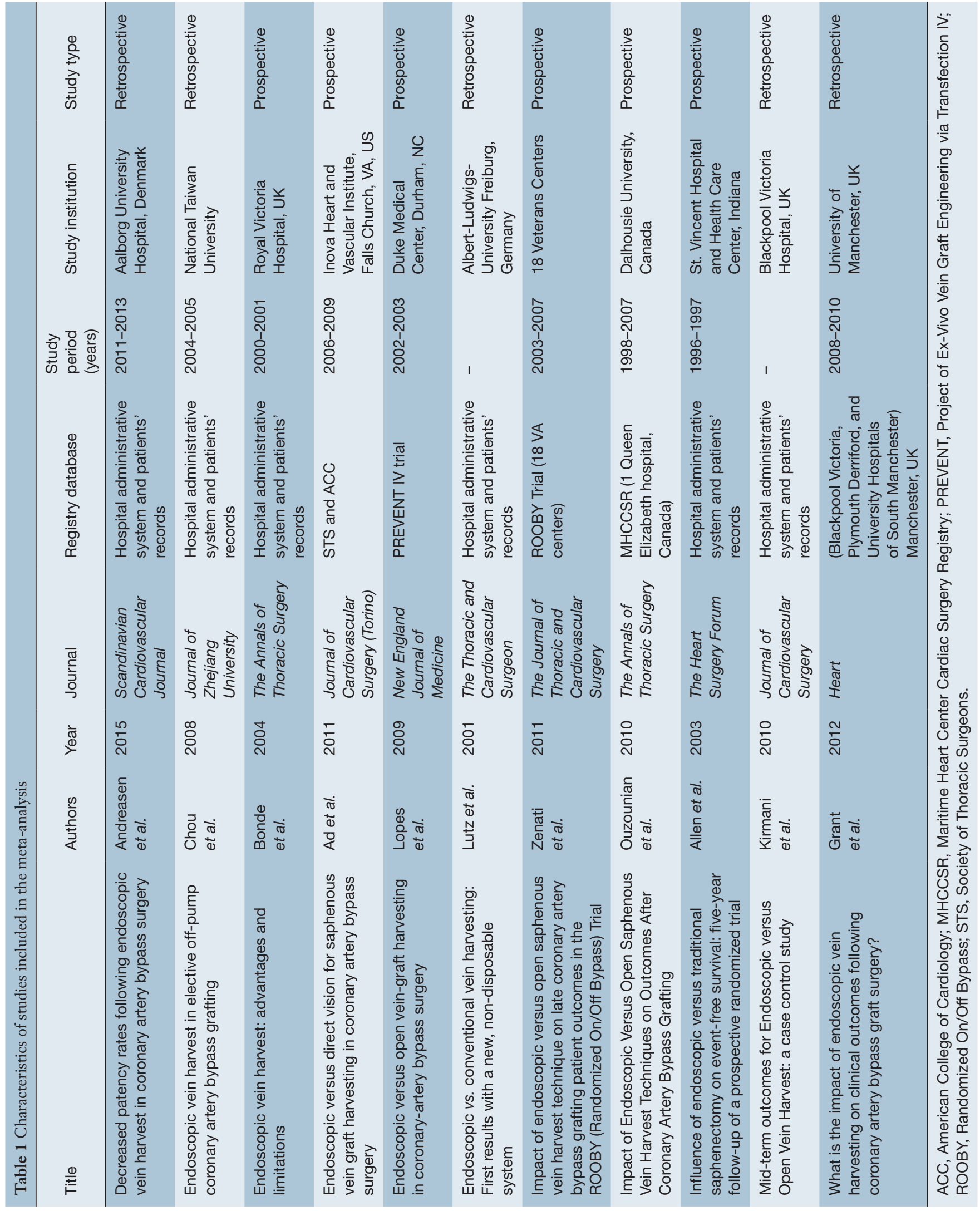


shown in Table 2. The mean age of patients in the open SVG harvest group was 65.3 years and in the endoscopic SVG harvest group was 64.4 years $(\mathrm{P}=0.64)$, with $>80 \%$ being male. Between patients undergoing CABG who underwent open or endoscopic SVG harvest, there were no significant differences in body mass index, smoking status, urgency of surgery, severity of coronary artery disease and comorbidities, including diabetes, hypertension, dyslipidemia, peripheral or cerebrovascular vascular disease, respiratory disease and renal failure.

\section{Operative details}

There were no significant differences in intraoperative variables between open and endoscopic SVG harvest, including concomitant valvular procedures, number of bypass grafts, SVG harvest time, vein graft length, graft injury, cardiopulmonary bypass and aortic cross clamp time, total operative time and hospital length of stay (Table 3).

\section{Postoperative morbidity}

Overall episodes of wound complication were significantly higher in patients who underwent CABG via open SVG harvest as compared to endoscopic SVG harvest [open $3.3 \%$ vs. endoscopic 1.1\%; OR: 0.02 (95\% CI, 0.01-0.06), $\mathrm{P}<0.001]$ (Table 4). Of wound complications, these were further subcategorized by leg infection [open $3.5 \%$ s. endoscopic 1.0\%; OR: 0.28 (95\% CI, 0.18-0.45), $\mathrm{P}<0.001$ requiring postoperative treatment with antibiotics [open $10.5 \%$ vs. endoscopic $0.0 \%$; OR: 0.08 (95\% CI, 0.01-0.58), $\mathrm{P}=0.01$ ], wound drainage [open $3.8 \%$ vs. endoscopic 0.2\%; OR: 0.14 (95\% CI, 0.03-0.76), $\mathrm{P}=0.02]$ and altered sensation [open $13.5 \%$ vs. endoscopic $2.0 \%$; OR: 0.23 (95\% CI, 0.08-0.65), $\mathrm{P}=0.01$ ]. There were no significant differences amongst the groups in terms of hematoma formation [open $13.9 \%$ vs. endoscopic $3.0 \%$; OR: 0.31 (95\% CI, 0.08-1.25), $\mathrm{P}=0.10$ ] and wound dehiscence [open $5.9 \%$ vs. endoscopic 0.6\%; OR: 0.22 (95\% CI, 0.02-2.16), $\mathrm{P}=0.19$ ]. Revision secondary to bleeding [open $2.5 \%$ vs. endoscopic 2.5\%; OR: 0.97 (95\% CI, 0.58-1.63), $\mathrm{P}=0.91$ ] and hospital readmission for various reasons [open $9.3 \% \mathrm{vs}$. endoscopic 9.0\%; OR: 0.83 (95\% CI, 0.54-1.26), $\mathrm{P}=0.37$ ] was also comparable between the two groups.

\section{Graft patency, myocardial infarction, and mortality}

The primary endpoint, graft patency per graft beyond one year, significantly favored open SVG harvest as compared to endoscopic SVG harvest for patients undergoing CABG surgery [open $82.3 \%$ vs. endoscopic $75.1 \%$; OR: 0.61 (95\% CI, 0.43-0.87), $\mathrm{P}=0.01$ ] (Table 4) (Figure 2).

Myocardial infarction in the 30 -day postoperative period [open 1.0\% vs. endoscopic 0.5\%; OR: 0.77 (95\% CI, 0.441.34), $\mathrm{P}=0.35$ ] and on long-term follow-up [open $1.7 \% \mathrm{vs.}$ endoscopic 1.5\%; OR: 1.04 (95\% CI, 0.68-1.60), $\mathrm{P}=0.85$ ] was similar between the two groups.

The 30-day postoperative mortality was significantly higher in patients who underwent CABG via open SVG harvest [open 3.4\% vs. endoscopic 2.1\%; OR: 0.59 (95\% CI, 0.37-0.94), $\mathrm{P}=0.03$ ] (Figure 3), with no significant differences in overall mortality [open $4.9 \%$ vs. endoscopic 4.9\%; OR: 0.80 (95\% CI, 0.50-1.27), $\mathrm{P}=0.34$ ] (Table 4).

\section{Discussion}

In this systematic review and meta-analysis of 18,131 patients undergoing CABG surgery, we demonstrate that the open SVG harvest technique appears to confer improved intermediate-term graft patency per graft as compared to endoscopic SVG harvest. However, patients with open SVG harvest had higher rates of early wound complications (infection, neuralgia) and postoperative 30-day mortality that importantly, did not translate to differences in overall mortality. Reasons for the higher postoperative 30-day mortality are unclear but may reflect variances in patient selection, severity of premorbid disease, urgency, hemodynamic stability, and timing of surgery.

Although a few studies comparing endoscopic and open SVG harvest have been published $(7,10,25,26)$, they are limited by low patient volume, lack of randomization, lack of angiographic assessment and short follow-up time during which clinically significant outcomes such as vein graft failure rates or major adverse cardiac outcomes may not yet become apparent. Maintaining long-term graft patency is the desired outcome as it is associated with long-term patient survival and reduces the need for reintervention (27).

In the post hoc sub-analysis of the PREVENT-IV trial (Project of Ex-Vivo Vein Graft Engineering via Transfection IV), endoscopic SVG harvest was associated with a higher rate of vein graft occlusion at 12 to 18 months and higher long-term mortality (12). A post hoc sub-analysis of the ROOBY trial (Randomized On/Off Bypass) (28) reported similar outcomes with lower vein graft patency and higher 1-year revascularization rates among patients who 


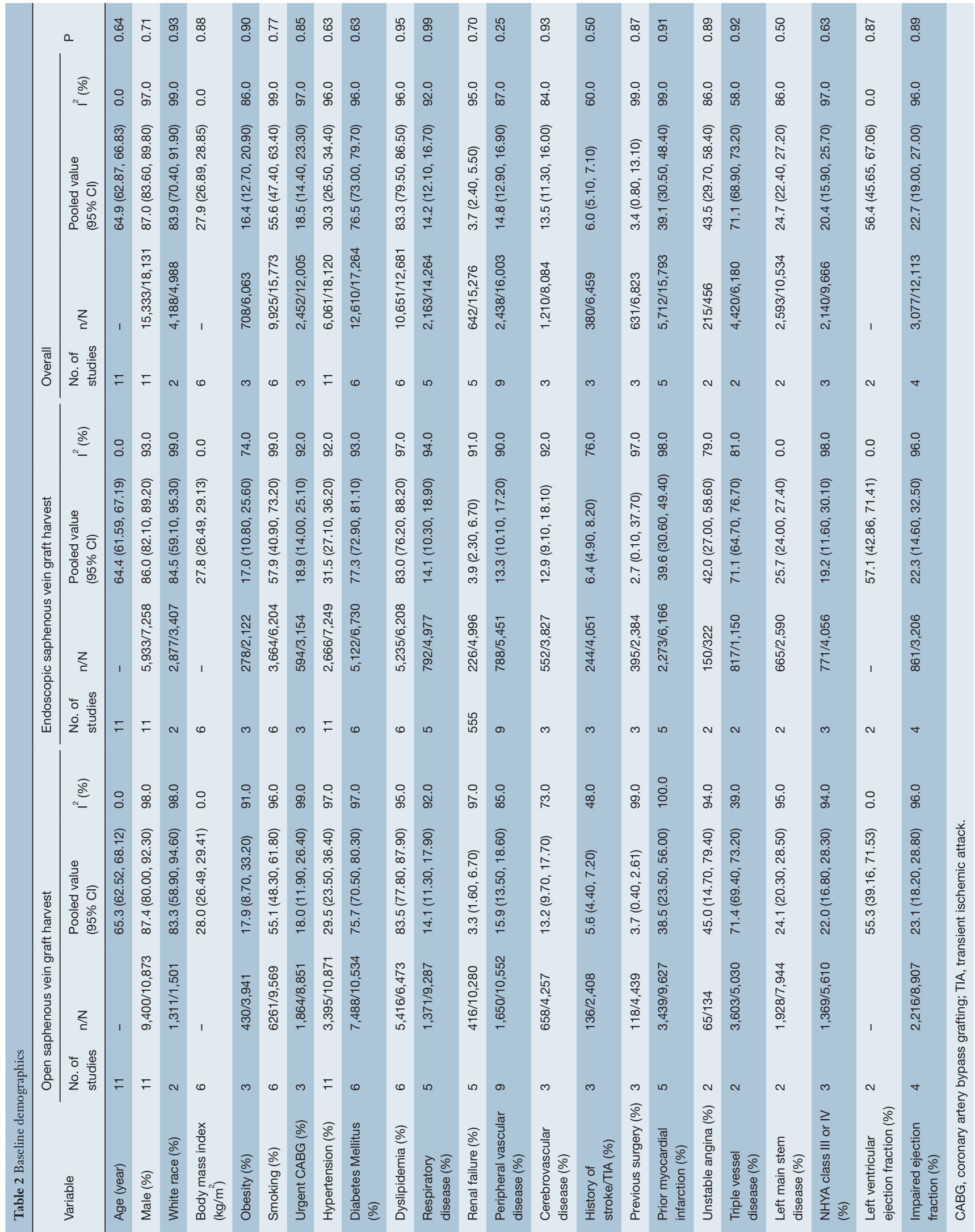




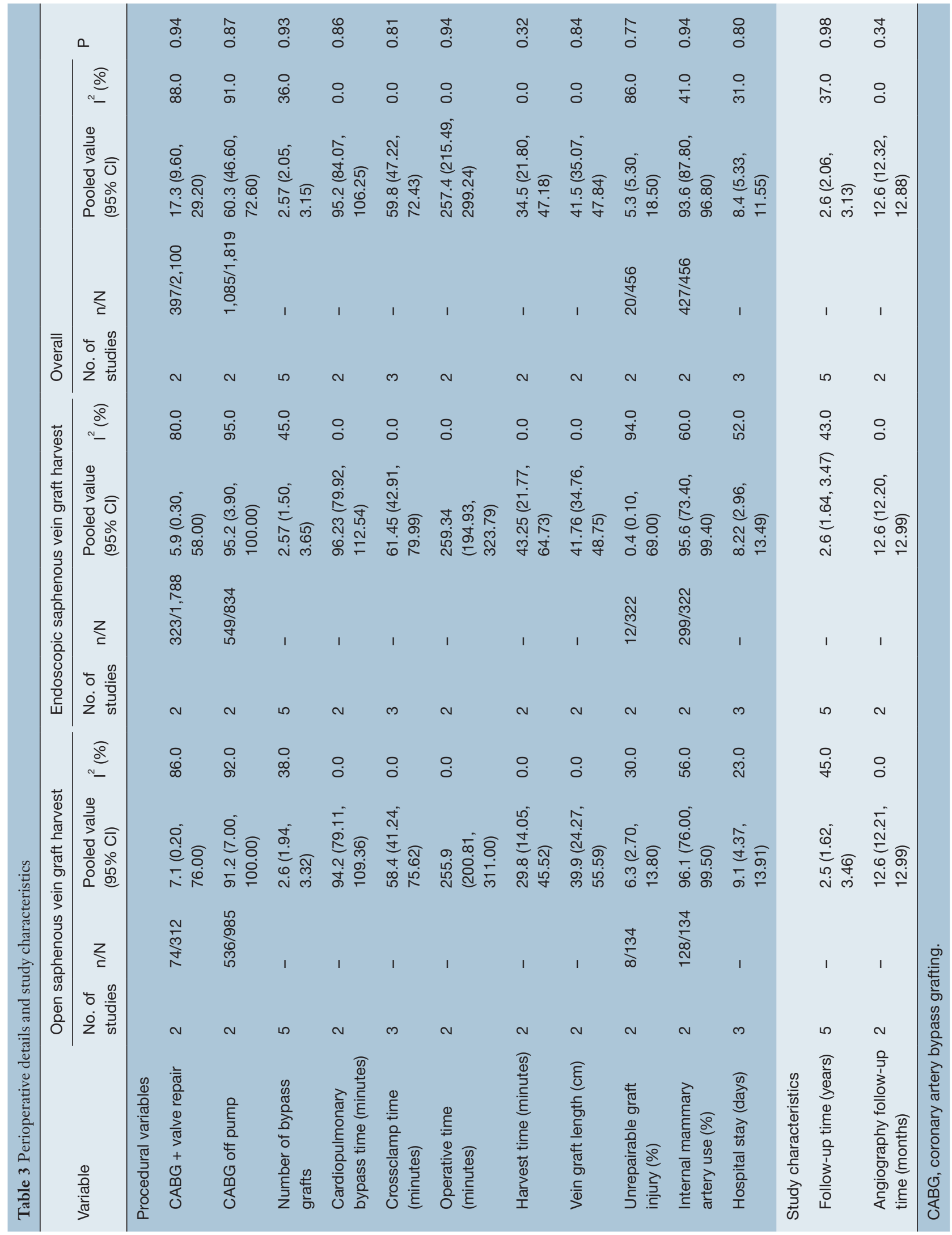




\begin{tabular}{|c|c|c|c|c|c|}
\hline Variable & $\begin{array}{l}\text { Open SVG } \\
\text { harvest, } \mathrm{n} / \mathrm{N}(\%)\end{array}$ & $\begin{array}{l}\text { Endoscopic SVG } \\
\text { harvest, n/N (\%) }\end{array}$ & $\begin{array}{l}\text { Odds } \\
\text { ratio }\end{array}$ & $95 \% \mathrm{Cl}$ & $\mathrm{P}$ \\
\hline \multicolumn{6}{|l|}{ Early outcomes } \\
\hline Revision for bleeding (\%) & $29 / 1,161(2.5)$ & $57 / 2,298(2.5)$ & 0.97 & $(0.58,1.63)$ & 0.91 \\
\hline Readmission (\%) & 29/312 (9.3) & $161 / 1,785(9.0)$ & 0.83 & $(0.54,1.26)$ & 0.37 \\
\hline \multicolumn{6}{|l|}{ Wound complications } \\
\hline Total episodes (\%) & $315 / 9,417$ (3.3) & $94 / 8,341(1.1)$ & 0.02 & $(0.01,0.06)$ & $<0.001$ \\
\hline Leg & $154 / 4,457(3.5)$ & $42 / 4,268(1.0)$ & 0.28 & $(0.18,0.45)$ & $<0.001$ \\
\hline Sternal & $38 / 3,940(1.0)$ & $21 / 2,117(1.0)$ & 0.75 & $(0.19,2.89)$ & 0.68 \\
\hline Hematoma & 29/209 (13.9) & 12/394 (3.0) & 0.31 & $(0.08,1.25)$ & 0.10 \\
\hline Wound drainage & $10 / 260(3.8)$ & $1 / 443(0.2)$ & 0.14 & $(0.03,0.76)$ & 0.02 \\
\hline Edema & 48/207 (23.2) & 8/398 (2.0) & 0.11 & $(0.04,0.32)$ & 0.23 \\
\hline Leg wound dehiscence & $8 / 136(5.9)$ & 2/324 (0.6) & 0.22 & $(0.02,2.16)$ & 0.19 \\
\hline Altered sensation & 28/208 (13.5) & 8/397 (2.0) & 0.23 & $(0.08,0.65)$ & 0.01 \\
\hline Infection treated with antibiotics (\%) & $12 / 114(10.5)$ & $0 / 106(0.0)$ & 0.08 & $(0.01,0.58)$ & 0.01 \\
\hline \multicolumn{6}{|l|}{ Late outcomes } \\
\hline Recurrent angina (\%) & $12 / 114(10.5)$ & 10/104 (9.6) & 0.91 & $(0.37,2.26)$ & 0.84 \\
\hline \multicolumn{6}{|l|}{ Myocardial infarction (\%) } \\
\hline Within 30 days & $43 / 4,133(1.0)$ & $20 / 3,789(0.5)$ & 0.77 & $(0.44,1.34)$ & 0.35 \\
\hline Overall & $43 / 2,357(1.8)$ & $63 / 4,220(1.5)$ & 1.04 & $(0.68,1.60)$ & 0.85 \\
\hline \multicolumn{6}{|l|}{ Mortality (\%) } \\
\hline Within 30 days & $178 / 5,222(3.4)$ & $93 / 4,442(2.1)$ & 0.59 & $(0.37,0.94)$ & 0.03 \\
\hline Overall & $136 / 2,790(4.9)$ & $222 / 4,558(4.9)$ & 0.80 & $(0.50,1.27)$ & 0.34 \\
\hline Graft patency per graft (\%) & $2,560 / 3,112(82.3)$ & 2,422/3,223 (75.1) & 0.61 & $(0.43,0.87)$ & 0.01 \\
\hline
\end{tabular}

A

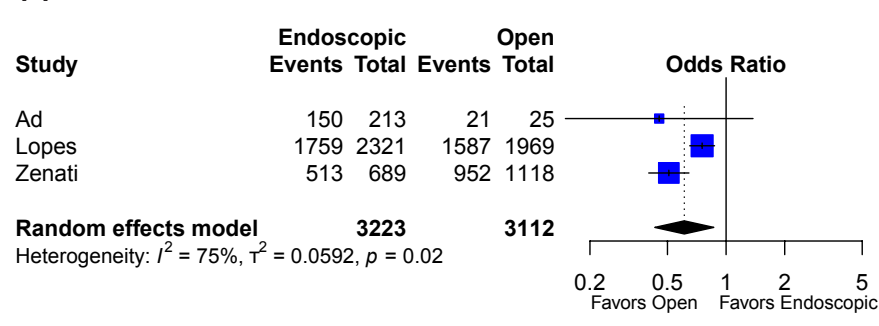

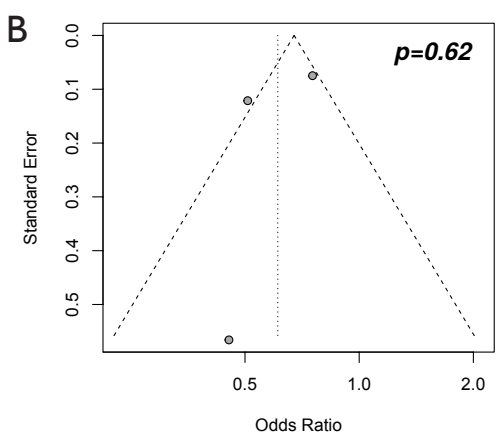

Figure 2 Graft patency per graft of open as compared to endoscopic saphenous vein grafting post coronary artery bypass grafting surgery (A) forest plot and (B) funnel plot. 

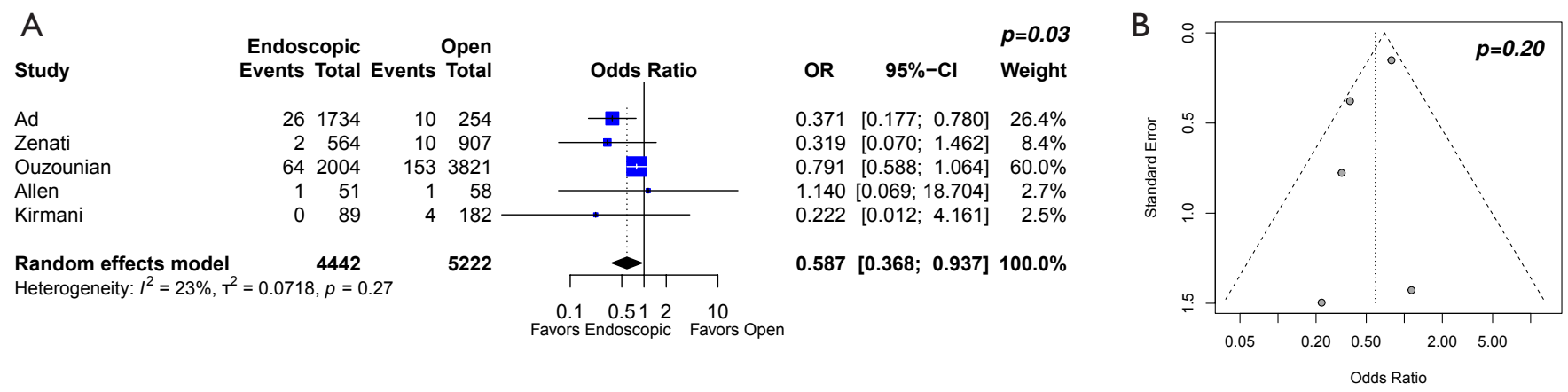

Figure 3 30-day post coronary artery bypass grafting mortality with open as compared to endoscopic saphenous vein grafting (A) forest plot and (B) funnel plot.

underwent endoscopic SVG harvest as compared to open SVG harvest. In the EPIC trial (Evaluation of the PASPort in Coronary Surgery) (29), worse SVG angiographic patency at 9 months was seen with endoscopic as compared to open SVG harvest. A propensity score adjusted analysis of the Society of Thoracic Surgeons National Database on Medicare patients (30), with a median follow-up of 3 years, reports no relationship between endoscopic SVG harvest and long-term mortality, or the composite endpoint of death, myocardial infarction and revascularization. In contrast, the Northern New England Cardiovascular Disease Study reports that endoscopic SVG harvest was associated with lower long-term mortality within 4 years of the index admission (31).

Endoscopic SVG harvest is not one homogenous procedure, although, due to the lack of granularity in the included studies, for the purposes of the present analysis they were pooled as one. Differences observed in prior studies may be due to differences in surgical technique (28), operator experience (32) and devices used $(28,33)$, which may influence vessel-harvesting-related injuries. More importantly, for post hoc sub-analyses of trials, it is vital to recognize that vein harvest technique was not the basis for randomization. As such, unrecognized confounding variables may be unaccounted for, such as on-pump $v s$. offpump CABG (28), with or without $\mathrm{CO}_{2}$ insufflation (34), as well as endoscopic SVG harvest devices used (29,33), pre $v$ s. post SVG harvest use of heparin (35), quality of distal target run-off $(9,36)$ which have all been shown to independently affect graft patency. Reduced graft patency with endoscopic SVG harvest could be related to intraoperative trauma with endoscopic manipulation of the graft leading to compromised functional integrity, poor vein quality and early occlusion (37). As well, thermal injury to the vessel wall can result from use of the bipolar cautery in endoscopic SVG harvest $(3,14,38)$.

At a histologic level, studies have shown that endoscopic manipulation of an SVG is associated with increased endothelial injury. A prospective, small study using multiphoton imaging, immunofluorescence and biochemical techniques has demonstrated increased endothelial damage and reduced viability in endoscopic SVG vein grafts (39). Furthermore, others have shown that endoscopically harvested SVG may undergo residual clotting and stranding, resulting in endothelial damage, infiltration of smooth muscle cells into the lamina and ultimately, graft thrombosis and failure (35), though these findings are not supported by all histologic studies $(6,40)$. Caution should be exercised when interpreting these histologic studies as they only reflect acute histologic features and not long-term histologic findings (12).

\section{Limitations}

This meta-analysis has several key limitations and must be interpreted with care. Heterogeneity was likely contributed to by differences among reports, between study populations, study design, definitions of adverse events, patient selection, site of vein graft harvest (thigh $v s$. calf), pre $v s$. post SVG harvest use of heparin, conduct of CABG with on-pump $v s$. off-pump technique, choice of distal target runoff, medical management of coronary artery disease and antithrombotic regime post $\mathrm{CABG}$, as well as postoperative angiographic follow-up to document graft patency. We acknowledge that this heterogeneity in study population is a fundamental limitation that cannot be addressed due to inability to extract sufficient detail from the pooled data. Moreover, the heterogeneity in results precludes broad generalization into 
prognostic terms.

Due to the lack of granularity in studies, we were unable to differentiate between different endoscopic SVG harvest techniques (open tunnel vs. closed tunnel with carbon dioxide insufflation), although it has previously been shown that there were no device-specific differences in clinical outcomes (33). Pooled results of CABG outcomes spanning 1982 to present may not correctly reflect the changes over the last 4 decades. Furthermore, although our goal was to evaluate long-term patency, limited follow-up from available studies only allowed for intermediate-outcome analysis. Despite these limitations, this systematic study aimed to assess the intermediate-term clinical and angiographic outcomes of SVG harvest for CABG via open as compared to endoscopic technique and in doing so, forms the basis for future studies.

\section{Conclusions}

The results of this systematic review and meta-analysis of 18,131 patients demonstrates superior SVG patency in patients who underwent CABG via open SVG harvest as compared to endoscopic SVG harvest at average followup time of 2.6 years. Patients with open SVG harvest had higher rates of early wound complications and postoperative 30-day mortality that importantly, did not translate to differences in overall mortality. Reasons for the higher postoperative 30-day mortality are unclear but may reflect variances in patient selection, urgency and severity of premorbid disease. Further studies to find and support methods to prevent graft failure are needed to evaluate the safety of endoscopic SVG harvest as compared to open SVG harvest in long-term angiographic and clinical outcomes. These studies should include large prospective randomized clinical trials that are adequately powered and take into account device-specific considerations.

\section{Acknowledgements}

None.

\section{Footnote}

Conflicts of Interest: The authors have no conflicts of interest to declare.

\section{References}

1. Hawkes AL, Nowak M, Bidstrup B, et al. Outcomes of coronary artery bypass graft surgery. Vasc Health Risk Manag 2006;2:477-84.

2. Al-Sabti HA, Al Kindi A, Al-Rasadi K, et al. Saphenous vein graft vs. radial artery graft searching for the best second coronary artery bypass graft. J Saudi Heart Assoc 2013;25:247-54.

3. Hashmi SF, Krishnamoorthy B, Critchley WR, et al. Histological and immunohistochemical evaluation of human saphenous vein harvested by endoscopic and open conventional methods. Interact Cardiovasc Thorac Surg 2015;20:178-85.

4. Cheng D, Allen K, Cohn W, et al. Endoscopic vascular harvest in coronary artery bypass grafting surgery: a meta-analysis of randomized trials and controlled trials. Innovations (Phila) 2005;1:61-74.

5. Markar SR, Hanna G. Minimally invasive esophagectomy for dysplastic Barrett's esophagus. World J Surg 2015;39:608-14.

6. Kiaii B, Moon BC, Massel D, et al. A prospective randomized trial of endoscopic versus conventional harvesting of the saphenous vein in coronary artery bypass surgery. J Thorac Cardiovasc Surg 2002;123:204-12.

7. Yun KL, Wu YX, Aharonian V, et al. Randomized trial of endoscopic versus open vein harvest for coronary artery bypass grafting: Six-month patency rates. J Thorac Cardiovasc Surg 2005;129:496-503.

8. Lumsden AB, Eaves FF, Ofenloch JC, et al. Subcutaneous, video-assisted saphenous vein harvest: report of the first 30 cases. Cardiovasc Surg 1996;4:771-6.

9. Markar SR, Kutty R, Edmonds L, et al. A meta-analysis of minimally invasive versus traditional open vein harvest technique for coronary artery bypass graft surgery. Interact Cardiovasc Thorac Surg 2010;10:266-70.

10. Allen KB, Heimansohn DA, Robison RJ, et al. Influence of endoscopic versus traditional saphenectomy on event-free survival: five-year follow-up of a prospective randomized trial. Heart Surg Forum 2003;6:E143-5.

11. Allen K, Cheng D, Cohn W, et al. Endoscopic Vascular Harvest in Coronary Artery Bypass Grafting Surgery: A Consensus Statement of the International Society of Minimally Invasive Cardiothoracic Surgery (ISMICS) 2005. Innovations (Phila) 2005;1:51-60.

12. Lopes RD, Hafley GE, Allen KB, et al. Endoscopic versus open vein-graft harvesting in coronary-artery bypass surgery. N Engl J Med 2009;361:235-244.

13. Ouzounian M, Hassan A, Buth KJ, et al. Impact of endoscopic versus open saphenous vein harvest techniques on outcomes after coronary artery bypass grafting. Ann 
Thorac Surg 2010;89:403-8.

14. Allen KB, Griffith GL, Heimansohn DA, et al. Endoscopic versus traditional saphenous vein harvesting: a prospective, randomized trial. Ann Thorac Surg 1998;66:26-31.

15. Athanasiou T, Aziz O, Skapinakis P, et al. Leg wound infection after coronary artery bypass grafting: a metaanalysis comparing minimally invasive versus conventional vein harvesting. Ann Thorac Surg 2003;76:2141-6.

16. Bitondo JM, Daggett WM, Torchiana DF, et al. Endoscopic versus open saphenous vein harvest: a comparison of postoperative wound complications. Ann Thorac Surg 2002;73:523-8.

17. Harky A, Balmforth D, Shipolini A, et al. Is endoscopic long saphenous vein harvesting equivalent to open harvesting technique in terms of graft patency? Interact Cardiovasc Thorac Surg 2017;25:323-6.

18. Furnary AP. Endoscopic saphenous vein harvesting: The good, the bad, and the ugly. J Thorac Cardiovasc Surg 2005;129:488-90.

19. Connolly MW, Poston RS. Endoscopic versus open veingraft harvesting. N Engl J Med 2009;361:1907-8; author reply 1909-10.

20. Aranki SF, Shopnick B. Endoscopic versus open vein-graft harvesting. N Engl J Med 2009;361:1907; author reply 1909-10.

21. Patel NN, Angelini GD. Surgery: Open or endoscopic vein graft harvesting-this is the question! Nat Rev Cardiol 2009;6:738-40.

22. Wolf RK, Alderman EL, Caskey MP, et al. Clinical and six-month angiographic evaluation of coronary arterial graft interrupted anastomoses by use of a self-closing clip device: a multicenter prospective clinical trial. J Thorac Cardiovasc Surg 2003;126:168-77.

23. Puskas JD, Thourani VH, Marshall JJ, et al. Clinical outcomes, angiographic patency, and resource utilization in 200 consecutive off-pump coronary bypass patients. Ann Thorac Surg 2001;71:1477-83; discussion 1483-4.

24. Sarzaeem MR, Mandegar MH, Roshanali F, et al. Scoring system for predicting saphenous vein graft patency in coronary artery bypass grafting. Tex Heart Inst J 2010;37:525-30.

25. Cheng DCH, Martin J, Ferdinand FD, et al. Endoscopic vein-graft harvesting: balancing the risk and benefits. Innovations (Phila) 2010;5:70-3.

26. Perrault LP, Jeanmart H, Bilodeau L, et al. Early quantitative coronary angiography of saphenous vein grafts for coronary artery bypass grafting harvested by means of open versus endoscopic saphenectomy: a prospective randomized trial. J Thorac Cardiovasc Surg 2004;127:1402-7.

27. Raja SG, Sarang Z. Endoscopic vein harvesting: Technique, outcomes, concerns and controversies. J Thorac Dis 2013;5:S630-7.

28. Zenati MA, Shroyer AL, Collins JF, et al. Impact of endoscopic versus open saphenous vein harvest technique on late coronary artery bypass grafting patient outcomes in the ROOBY (Randomized On/Off Bypass) Trial. J Thorac Cardiovasc Surg 2011;141:338-44.

29. Puskas JD, Halkos ME, Balkhy H, et al. Evaluation of the PAS-Port Proximal Anastomosis System in coronary artery bypass surgery (the EPIC trial). J Thorac Cardiovasc Surg 2009;138:125-32.

30. Williams JB, Peterson ED, Brennan JM, et al. Association between endoscopic vs open vein-graft harvesting and mortality, wound complications, and cardiovascular events in patients undergoing CABG surgery. JAMA 2012;308:475-84.

31. Dacey LJ, Braxton JH, Kramer RS, et al. Long-Term Outcomes of Endoscopic Vein Harvesting After Coronary Artery Bypass Grafting. Circulation 2011;123:147-53.

32. Desai P, Kiani S, Thiruvanthan N, et al. Impact of the learning curve for endoscopic vein harvest on conduit quality and early graft patency. Ann Thorac Surg 2011;91:1385-91; discussion 1391-2.

33. van Diepen S, Brennan JM, Hafley GE, et al. Endoscopic harvesting device type and outcomes in patients undergoing coronary artery bypass surgery. Ann Surg 2014;260:402-8.

34. Lin TY, Chiu KM, Wang MJ, et al. Carbon dioxide embolism during endoscopic saphenous vein harvesting in coronary artery bypass surgery. J Thorac Cardiovasc Surg 2003;126:2011-5.

35. Brown EN, Kon ZN, Tran R, et al. Strategies to reduce intraluminal clot formation in endoscopically harvested saphenous veins. J Thorac Cardiovasc Surg 2007;134:1259-65.

36. Widimsky P, Straka Z, Stros P, et al. One-year coronary bypass graft patency: a randomized comparison between off-pump and on-pump surgery angiographic results of the PRAGUE-4 trial. Circulation 2004;110:3418-23.

37. Souza DS, Arbeus M, Botelho Pinheiro B, et al. The notouch technique of harvesting the saphenous vein for coronary artery bypass grafting surgery. Multimed Man Cardiothorac Surg 2009;2009:mmcts.2008.003624.

38. Bazin JE, Gillart T, Rasson P, et al. Haemodynamic 
conditions enhancing gas embolism after venous injury during laparoscopy: A study in pigs. Br J Anaesth 1997;78:570-5.

39. Rousou LJ, Taylor KB, Lu XG, et al. Saphenous Vein Conduits Harvested by Endoscopic Technique Exhibit

Cite this article as: Kodia K, Patel S, Weber MP, Luc JG, Choi JH, Maynes EJ, Rizvi SS, Horan DP, Massey HT, Entwistle JW, Morris RJ, Tchantchaleishvili V. Graft patency after open versus endoscopic saphenous vein harvest in coronary artery bypass grafting surgery: a systematic review and meta-analysis. Ann Cardiothorac Surg 2018;7(5):586-597. doi: 10.21037/ acs.2018.07.05
Structural and Functional Damage. Ann Thorac Surg 2009;87:62-70.

40. Griffith GL, Allen KB, Waller BF, et al. Endoscopic and traditional saphenous vein harvest: A histologic comparison. Ann Thorac Surg 2000;69:520-3. 